One example which casts doubt on the scientific validity of the guidelines is the comment "Benzodiazepines are not suitable for use in combination products." This extreme and unjustifiable pronouncement effectively abolishes all future research in this field (and who knows what clinical benefits may await present or future benzodiazepines coupled with some other known or unknown compound?), and in respect of current products it casts a judgment without allowing debate.

ERIC S SNELI

Association of the British Pharmaceutical Industry, London W1R 6DD

\section{Kidney biopsy}

SIR,-The very clear description of the technique of renal biopsy (23 February, p 547) worries me because the authors imply that the procedure could be used in many hospitals. There are two reasons why this should not be so.

Firstly, to maintain competence in the procedure one needs to perform at least two biopsies each month. General medical wards are unlikely to provide sufficient patients for a single member of a firm to achieve or maintain expertise in kidney biopsy. Secondly, it is unfair to ask a pathologist to make a reasonable diagnosis unless he is reporting on at least 30 renal biopsies annually. In addition light microscopy alone even in the best hands is inadequate for diagnosis. Immunofluorescent or immunoperoxidase studies and electron microscopy are essential for full morphological analysis. These techniques are only possible with the help of highly trained and skilled technical staff. Kidney biopsy is therefore a team procedure and every hospital cannot have such teams.

Department of Renal Medicine,

Roger GABRIEI

St Mary's Hospital,
London W2 1NY

SIR,-It is a great pity that recent contributions on needle biopsy of the kidney (23 February, p 547) and liver (15 March, p 776) should recommend a procedure at variance with that proposed by the manufacturers of the Tru-Cut needle. The instructions supplied with the needles were amended to improve safety, and operators should consult and comply with them.

The disposable Tru-Cut needle was introduced and became popular without formal comparison with the reusable Menghini needle. It is very much more expensive, and certainly for liver biopsy confers no advantage. ${ }^{1}$

MaLColm C Bateson

University Department of Medicine,

Ninewells Hospital
Dundee DD1 9SY

Bateson MC, Hopwood D, Duguid HLD, Bouchier
IAD. $f$ Clin Path 1980;33:131-3.

SIR,-I noted your correction (8 March, p 700) to the table of contraindications to kidney biopsy (23 February, p 547); however, I feel that some of the haematological data still require comment.

A prothrombin time of greater than or equal to 16 seconds may be a contraindication, although a safer limit would be "not greater than 2-3 seconds longer than the time for control plasma" (which is from a pool of normal plasma samples and which may give times as short as 11 seconds, depending on the thromboplastin used in the test). Recording the result of the test plasma as a ratio of the control value is a recommended method. ${ }^{1}$

The expression of the platelet count $\times 10^{10} / 1$ [added in the subediting-ED, $B M F$ ] is unfortunate when the conventional factor is $\times 10^{9} / 1,^{23}$ the contraindication then becoming a platelet count under $100 \times 10^{9} / 1$ One useful simple screening test in renal disease is the bleeding time, ${ }^{4}$ which helps to detect abnormal platelet function (the major factor contributing to the haemostatic defect of uraemia). Abnormalities of platelet retention (in glass bead filters) and platelet factor 3 availability (decrease often associated with abnormal platelet aggregation) have been found in a variable percentage of uraemic patients by most investigators. ${ }^{5}$ In general, however, these defects are observed in patients with clinically noteworthy bleeding and usually disappear after peritoneal dialysis or haemodialysis. ${ }^{6}$

Royal Marsden Hospital,

R G HUGHES

London SW3 6JJ

${ }^{1}$ Poller L. Association of Clinical Pathologists Broadsheet 1970;No 71 .

Baron DN, Broughton PMG, Cohen M, Lansley TS, Lewis

ICSM, IFCC, WAPS. Br $\mathcal{F}$ Haematol 1972;23:787-8. Ivy AC, Nelson D, Bucher G. $尹$ Lab Clin Med 1940; 26:1812-22

Weiss HJ. In: Williams WJ, Beutler E, Ersler AJ, Rundles RW, eds. Haematology.

- Rabiner SF. Prog Hemostasis Thromb 1972;1 :233-50.

\section{Vitamin D supplements in Asian women}

SIR,-Dr O G Brooke and others (15 March, p 751) report a better calcium status in babies born to Asian women whose diets were supplemented by calciferol $1000 \mathrm{IU} /$ day during pregnancy. The recommendation is therefore to give calciferol to pregnant Asian women. Before such a recommendation is adopted on a wide scale further information must be provided. If allocation to the trial were on a random basis, why at the end of the trial were there 67 women in the control group and 59 in the treatment group? Patients were excluded from the trial for reasons such as preterm deliveries and congenital malformation. Was there a higher incidence in these complications in babies born to mothers receiving the calciferol supplement, and if so can an explanation be provided?

East Birmingham Hospital,

J G BISSENDEN

$*_{*}^{*}$ We sent a copy of this letter to the author, whose reply is printed below.-ED, $B M F$.

SIR,-We thank Dr Bissenden for his interest and respond to his questions as follows:

(1) In all, 135 women entered the trial. They were allocated at random by the hospital pharmacy on the basis of their hospital numbers, and there were initially 63 in the treatment group and 72 in the control group. Simple statistical analysis shows that there is a $5 \%$ chance that the size of one of the groups could be less than 56 or greater than 79 . Our group sizes were thus well within these limits.

(2) Three women in the control group and two in the treatment group withdrew, either because they moved to other areas before delivery or because they decided not to continue with the trial. Other exclusions were as follows: in the control group there was one preterm delivery and one neonatal death due to intrapartum anoxia and meconium aspiration; in the treatment group one woman was excluded because she developed gestational diabetes; and one infant had spina bifida. There is thus no evidence of a higher incidence of complications in the treatment group.

O G BROOKE I R F BROWN

St George's Hospital Medical School, London SW 17 ORE

\section{Polypharmacy in rheumatic diseases}

SIR,-We were pleased to read in your leading article (8 March, p 666) "Polypharmacy in rheumatic diseases" that the plasma half lives of drugs tend to be longer in older patients. We wish more pharmaceutical companies took notice of this statement, and would like to emphasise the need to establish the pharmacokinetic profile of various drugs in the older population before launching the sales of these drugs. It is well established that the older population is the major consumer of drugs, ${ }^{12}$ in particular the antirheumatic agents, and yet when one screens the literature one is appalled by the paucity of information regarding the biological handling of these drugs by elderly patients. In fact, most of these parameters seem to be measured only in young healthy volunteers. Is it reasonable to extrapolate the findings to the older population, when it is well known that as the individual ages the intestinal mucosal surface area decreases, ${ }^{3}$ the blood supply to the gastrointestinal tract decreases, ${ }^{4}$ the hepatic and renal clearances become impaired, ${ }^{4}$ the binding of drugs to plasma protein seems altered, ${ }^{\circ}$ and the number of receptor sites on the target organs may well also decrease??

We feel that clinicians should insist on knowing the pharmacokinetic profile of the various drugs they prescribe to their elderly patients and we look forward to the time when this information will become an integral part of the work done on any drug before it is marketed.

R HAMDY

N H PERERA

M WHITWORTH

Department of Clinical Gerontology, St John's Hospital,

\section{${ }^{1}$ Crooks J, Shepherd A, Stevenson I. Health Bulletin 1975;33:222-7. ? Williamson J. Practitioner 1978;220:749-55. \\ Warren PM. Lancet 1978;ii:849-50. \\ Richey DP. In: Goldman R, Rockstein M, Sussman M, eds. The physiology and pathology of human ageing New York: Academic Press, 1975 . \\ Mrug treatment T, T, Crooks J. In: Avery GS ed. pharmacology and therapeutics. Sydney: Adis Press, pharmacology \\ - Stevenson IH, Shepherd AM. Br 7 Clin Pract 1978; \\ ' Roth GS. Fed Proc 1979;38:1910-4.}

\section{Trimethoprim resistance in Finland}

SIR,-Mr $\mathbf{P}$ Huovinen and Professor $\mathbf{P}$ Toivanen reported (12 January, $p$ 72) that in 1978 , after five years' use of plain trimethoprim in the Turku area, the incidence of trimethoprim-resistant Escherichia coli isolated from urines was $11 \%$ and $23 \%$ in outpatients and inpatients respectively. By contrast, the inci- 